\title{
Comparative Analysis of the Effects of Financial Development on Industry Agglomeration in the Different Regions of China with Panel Data Model
}

\author{
Xiaowei Yang ${ }^{1}$ and Jianjun $\mathrm{Xu}^{2}$ \\ ${ }^{1}$ Ningbo City College of Vocational Technology, Ningbo, 315000, PR. China \\ ${ }^{2}$ Institute of Science and Technology Ningbo University, Ningbo, 315211, P.R. China
}

\begin{abstract}
This paper constructs the cross-provinces panel data model to analyze the effects of financial development on industrial agglomeration from the financial scale, financial structure and financial efficiency respectively. The results show that the effects of financial development on industrial agglomeration in the eastern, central and western regions are significantly different. In which, financial scale is conducive to manufacturing agglomeration in East area, financial scale is not conducive to manufacturing agglomeration in West area, the effects of financial scale on manufacturing agglomeration is not significantly in central area. The financial structure of the East region cannot adapt the development of manufacturing agglomeration, and the effects of the financial structure of the Middle and West region on manufacturing agglomeration are not significant; the financial efficiency is not conducive to manufacturing agglomeration in the East region, the financial efficiency is conducive to manufacturing agglomeration in the West region, the effect of the financial efficiency in the Middle region on manufacturing agglomeration is not significant.
\end{abstract}

Keywords-financial development; industrial agglomeration; panel data model

\section{INTRODUCTION}

With the rapid growth of China's economy, various industrial zones emerge abound. The formation mechanism of Chinese industrial agglomeration draws the attention of a large number of scholars. Liu Xiuyan et al (2007)[1], Han and $\mathrm{Ke}(2013)$ [2] confirmed the market capacity, market potential, urbanization, infrastructure facilities, the role of government and other factors on China's manufacturing industry agglomeration in the new economic geography framework respectively. Wang and Fang (2010)[3], Wu and Li (2010)[4] analyzed of the geographic location, labor costs and other factors of comparative advantage for the development of China's industrial agglomeration effects in the framework of neoclassical trade theory. Gao Ting(2004)[5], Le Hanbin (2011)[6] and others confirmed that the opening of factors, such as export and foreign investment, promoted China's industrial agglomeration. $\mathrm{Lu}$ and Tao(2007)[7], Bosker et al(2010)[8] analyzed the impact of the factors associated with institution, such as local protection, the household registration system etc, on the extent of China's industrial agglomeration. In short, a number of literatures had shown that the formation of China's industrial agglomeration is the result of numerous factors contributed. To further understand the in-deep reasons behind China's industrial agglomeration, it requires innovation and exploration.

In recent years, financial factors affecting China's industrial agglomeration began to receive attention. The corresponding literature is increasing. Ma Runping (2012) [9]constructed the panel data, including 13 cities of Jiangsu province from 2000 to 2010 and analyzed the impact of the financial structure on the industrial agglomeration. The results showed the structure of indirect financing and securities financing both significantly promoted the industrial agglomeration in Jiangsu province, but the insurance industry didn't promote industrial agglomeration of Jiangsu province; Combined with 20 provinces in China from 1991-2007, Zhang and Wang (2010)[10] analyzed the relationship between the entrepreneurship and industrial agglomeration. The results showed that the higher the efficiency of financial markets, the density of entrepreneurs is relatively high, and the scale and industrial agglomeration effect were relatively obvious; Guo and Duan (2011) [11] selected of 31 provinces from1999-2009 and built a dynamic panel data model to analyze the effects of different endowments on China's industrial agglomeration. The results showed that the financial elements of the eastern and central areas have a significant role in promoting of industry concentration, while the promoting effect of financial elements on the Western industrial agglomeration is not significant.

Although the above literature data used different methods to confirm the influence of financial factors on industrial agglomeration, but few literature depth analyze the effects of size, structure and efficiency of financial development on industrial agglomeration. Different from the previous studies, this paper built cross-provincial panel model to analyze the effect of financial size, financial structure and financial efficiency to industry agglomeration and their regional differences. This will help us have a more comprehensive understanding of the role of financial support in the process of industrial agglomeration.

\section{ECONOMETRIC MODEL, VARIABLES AND DATA}

For an in-depth analysis of the effect of China's financial development on industrial agglomeration, following $\mathrm{Ma}$ Xuejiao (2012)[9], we take manufacturing cluster indicators $\left(\mathrm{LQ}_{\mathrm{it}}\right)$ as explanatory variables, financial development 
indicators (fin(i)it) as the main explanatory variable and 5 important factors in affecting the manufacturing industry clusters as control variables $\left(\mathrm{CV}_{\mathrm{it}}\right)$ to construct the following econometric model to analyze the effect of financial development on manufacturing industry agglomeration.

In order to analyze the characteristics of regional differences about the influence of financial development on industry agglomeration, we also built a model including interaction as follows:

$$
\ln L Q_{\mathrm{it}}=\alpha_{0}+\beta_{\mathrm{i}} \ln f i n(\mathrm{i})_{\mathrm{it}}+\varphi_{\mathrm{i}} \mathrm{d}(\mathrm{j})_{\mathrm{it}}+\lambda_{\mathrm{i}} \mathrm{D}(\mathrm{j})_{\mathrm{it}} * \ln f i n(\mathrm{i})_{\mathrm{it}}+\gamma_{\mathrm{i}} \sum_{\mathrm{i}=\mathrm{i}}^{\mathrm{n}} \ln C \mathrm{~V}_{\mathrm{it}}+\varepsilon_{\mathrm{it}}(1)
$$

We use the location quotient (LQ) indicators to measure the degree of concentration of manufacturing industry. Variable LQit indicates No.i unit as the manufacturing industry concentration degree in the $t$ period. The following is the calculation formula:

$$
\mathrm{LQ}_{\mathrm{it}}=\left[\left(\mathrm{E}_{\mathrm{ij}} / \mathrm{E}_{\mathrm{i}}\right) /\left(\mathrm{E}_{\mathrm{kj}} / \mathrm{E}_{\mathrm{k}}\right)\right]_{\mathrm{t}}
$$

Among them, the $E_{i j}$ is the $\mathrm{j}$-th manufacturing industries in $\mathrm{i}$ province; $E_{i}$ is the total industrial output of all manufacturing industries in the $\mathrm{i}$-th province $\mathrm{I}$; Ekj is the $\mathrm{j}$-th industrial production for the $\mathrm{k}$-th nationwide manufacturing sector. Ek is the gross output value of industrial enterprises in nationwide $\mathrm{k}$. The location entropy of manufacturing industry includes 20 manufacturing industry, such as textile, oil processing and the coking industry, ferrous metal smelting and the pressure extended processing and so on.

We can investigate the level of financial development in a country or region (fin(i)) from the views of the financial scale, financial structure and financial efficiency. A reference to the practices of Ran Guanghe et al(2011)[12], We build the indicators of financial development scale (finsize) in different provinces. the indicators of the financial development scale equals the amount of bank intermediary institutions' credit and financial markets directly funding divided by second industry of nominal gross domestic production(GDP); Financial structure indicators (finstru) equals the amount of bank intermediary credit divided by the total financing amount from bank intermediary credit and financial markets funding. The financial efficiency indicator (fineffi) equals loans divided by saving coming from the financial intermediaries, which also reflect the conversion capabilities of the savings-investment.

The meaning of the explanatory variables and the main explanatory in the model is same with the model (1), virtual variables $\mathrm{D}(\mathrm{j})$ reflecting differences in Eastern, Central and Western regions are defined as follows:

$$
D(j)_{i t}= \begin{cases}1 & \text { i province in } \mathrm{j} \text { region } \\ 0 & \mathrm{i} \text { province not in } \mathrm{j} \text { region }\end{cases}
$$

Where $\mathrm{j}(=1,2,3)$ region indicates Eastern, Central and Western regions respectively. Meanwhile, we use interactive items $(D(j) *$ Lnfin(i)) to reflect the scale, structure and efficiency differences of financial development in East, and Central and West region, which consists of virtual variable $D(j)$ product financial development indicators (fin (i)). Financial scale, financial structure and financial efficiency remember for $\mathrm{D}(\mathrm{j})$ *Infinsize, $\mathrm{D}(\mathrm{j})$ it * Infinstru and $\mathrm{D}(\mathrm{j}) *$ Infineffi respectively. In which, control variables include export trade, economic infrastructure, workforce size, urbanization and service conditions. Constructional method of each indicator is described below:

Export trade (export) indicated by a degree of dependence on exports, that is the exports/GDP; economic foundation (avggdp) approximate equals per capita GDP, calculated from GDP divided by the total population; labor force (labor) represented by the total labor force at the end of the year; the process of urbanization (citiliza) represented by the urbanization rate, divided by urban and rural population; service level (service) expressed in relative size in services industry, which equals the output value of the tertiary industry divided by GDP of the province.

The sample of this study consists of 31 provincial-level administrative units in mainland China, the time span from 2000 to 2011, the underlying data taking from the China Industrial Economic Yearbook, the Statistical Yearbook of China, the China Finance Yearbook, the China Population Statistical Yearbook, the Yearbook of China's Regional Economic Statistics and Wind.

\section{QUANTITATIVE ANALYSIS RESULTS AND INTERPRETATION}

In order to further examine regional differences in effects of financial development on industry agglomeration, we further, according to the model (1), use panel EGLS cross-sectional weighting method to estimate the mixing effect of the financial scale, financial structure and financial efficiency on the agglomeration of manufacturing industry. The results are shown in Table I. The estimated results in Table I indicate that, after adding the indicators reflecting geographical differences of Eastern, Middle and Western and reflecting regional difference of financial development levels of three major indicators on financial development, the estimated parameter of the impact of financial size, financial structure and financial efficiency on industry cluster also are positive respectively, and further raise the significance level of the estimated parameters. Compare with the difference of impact of geographical differences in Eastern, Middle and Western on industrial agglomeration, we know that there are significant differences about the effect of the geographical location in the Eastern, Central and Western on industry agglomeration. The estimated parameters of virtual variables D1 in $\mathrm{M}(1), \mathrm{M}(4)$ and $\mathrm{M}(7)$ are positive, and the arguments of $\mathrm{M}(1)$ and $\mathrm{M}(4)$ have passed the significance test at the $1 \%$ level, suggesting that manufacturing industry located in the eastern coastal provinces has an advantage on the spatial agglomeration. The estimated coefficients of D2 in $\mathrm{M}(2), \mathrm{M}(5)$ and $\mathrm{M}(8)$ are negative, but not pass the $t$ tests, this indicates that the central location does not have a significant impact on manufacturing cluster. The estimated coefficients of D3it in $\mathrm{M}(3)$ and $\mathrm{M}(6)$ are significantly negative, suggesting that geographic location itself 
is detrimental to the spatial agglomeration of manufacturing industry in the West.

Next, in order to analyze the differences effect of the nonequilibrium of financial development on agglomeration of manufacturing industry in Eastern, Middle and Western, we compare $\mathrm{M}(1)-\mathrm{M}(3), \mathrm{M}(4)-\mathrm{M}(6)$ and $\mathrm{M}(7)-\mathrm{M}(9)$ respectively.

TABLE I. THE IMPACT OF FINANCIAL DEVELOPMENT ON MANUFACTURING INDUSTRY AGGLOMERATION IN DIFFERENT REGIONS

\begin{tabular}{|c|c|c|c|c|c|c|c|c|c|}
\hline & \multicolumn{3}{|c|}{ Financial scale } & \multicolumn{3}{|c|}{ Financial structure } & \multicolumn{3}{|c|}{ Financial efficient } \\
\hline & east & middle & west & east & middle & west & east & middle & west \\
\hline & $\mathrm{M}(1)$ & $\mathrm{M}(2)$ & $\mathrm{M}(3)$ & $M(4)$ & $M(5)$ & M (6) & $M(7)$ & $\mathrm{M}(8)$ & $M(9)$ \\
\hline \multirow{2}{*}{ lnfinsize } & $0.090 * * *$ & $0.051 * * *$ & 0.018 & & & & & & \\
\hline & 5.966 & 3.234 & 0.827 & & & & & & \\
\hline \multirow{2}{*}{ lnfinstr } & & & & $-0.019 * * *$ & $-0.004 *$ & -0.003 & & & \\
\hline & & & & -5.544 & -1.829 & -1.045 & & & \\
\hline \multirow{2}{*}{ Infineffi } & & & & & & & $0.035^{* *}$ & 0.014 & 0.009 \\
\hline & & & & & & & 2.106 & 1.491 & 0.558 \\
\hline \multirow{2}{*}{$D(j)$} & $0.020 * * *$ & $0.015 * * *$ & $0.018 * * *$ & $0.031 * * *$ & $0.018 * * *$ & $0.020 * * *$ & $0.023 * * *$ & $0.016 * * *$ & $0.018^{* * *}$ \\
\hline & 4.065 & 4.379 & 3.900 & 6.159 & 5.087 & 4.209 & 4.888 & 4.771 & 3.981 \\
\hline \multirow{2}{*}{$\begin{array}{c}\mathrm{D}(\mathrm{j}) \\
\times \operatorname{lnfinsize}\end{array}$} & $0.049 * * *$ & $0.045 * * *$ & $0.033 * * *$ & $0.052 * * *$ & $0.034 * * *$ & $0.032 * * *$ & $0.049 * * *$ & $0.034 * * *$ & $0.032 * * *$ \\
\hline & 5.202 & 4.059 & 3.008 & 5.678 & 3.395 & 3.023 & 5.360 & 3.381 & 2.967 \\
\hline \multirow{2}{*}{$\begin{array}{c}\mathrm{D}(\mathrm{j}) \\
\times \text { lnfinstru }\end{array}$} & $0.079 * * *$ & 0.050 & $0.064 * * *$ & $0.061 * * *$ & $0.089 * *$ & $0.064 * * *$ & $0.063 * * *$ & $0.088^{*}$ & $0.061 * *$ \\
\hline & 12.919 & 0.986 & 2.677 & 10.187 & 1.917 & 2.819 & 11.699 & 1.871 & 2.482 \\
\hline \multirow{2}{*}{$\begin{array}{c}\mathrm{D}(\mathrm{j}) \\
\times \text { lnfineffi }\end{array}$} & $0.049 * * *$ & 0.008 & $0.031 *$ & $0.053 * * *$ & 0.003 & $0.031 *$ & $0.058 * * *$ & 0.005 & $0.031 *$ \\
\hline & 2.785 & 0.631 & 1.783 & 3.016 & 0.289 & 1.776 & 3.266 & 0.397 & 1.747 \\
\hline \multirow{2}{*}{ Inexport } & $0.030 *$ & $0.057 * * *$ & $0.061 * * *$ & $0.078 * * *$ & $0.056 * * *$ & $0.066 * * *$ & $0.063 * * *$ & $0.055 * * *$ & $0.064 * * *$ \\
\hline & 1.788 & 3.851 & 3.653 & 5.457 & 4.085 & 4.024 & 4.506 & 4.003 & 3.947 \\
\hline \multirow{2}{*}{ lnavggdp } & $-0.497 * * *$ & -0.292 & $-0.330^{*}$ & $-0.310 * * *$ & -0.551 & $-0.324 *$ & $-0.245^{* * *}$ & -0.527 & -0.294 \\
\hline & -8.784 & -0.781 & -1.810 & -6.711 & -1.590 & -1.878 & -6.083 & -1.499 & -1.564 \\
\hline \multirow{2}{*}{ lnlabor } & 0.399 & 0.799 & 0.083 & 0.354 & 0.794 & 0.087 & 0.352 & 0.793 & 0.079 \\
\hline & 0.389 & 0.778 & 0.068 & 0.343 & 0.772 & 0.072 & 0.341 & 0.771 & 0.064 \\
\hline \multirow{2}{*}{ Incitiliza } & 40.348 & 37.093 & 5.537 & 33.045 & 35.799 & 5.742 & 33.037 & 35.652 & 5.213 \\
\hline & $0.090 * * *$ & $0.051 * * *$ & 0.018 & & & & & & \\
\hline \multirow{2}{*}{ Inservice } & 5.966 & 3.234 & 0.827 & & & & & & \\
\hline & & & & $-0.019 * * *$ & $-0.004 *$ & -0.003 & & & \\
\hline \multirow{2}{*}{$\mathrm{C}$} & & & & -5.544 & -1.829 & -1.045 & & & \\
\hline & & & & & & & $0.035 * *$ & 0.014 & 0.009 \\
\hline R-sq & & & & & & & 2.106 & 1.491 & 0.558 \\
\hline Adj.R-sq & $0.020 * * *$ & $0.015^{* * *}$ & $0.018 * * *$ & $0.031^{* * *}$ & $0.018 * * *$ & $0.020 * * *$ & $0.023 * * *$ & $0.016^{* * *}$ & $0.018 * * *$ \\
\hline F-stat. & 4.065 & 4.379 & 3.900 & 6.159 & 5.087 & 4.209 & 4.888 & 4.771 & 3.981 \\
\hline
\end{tabular}

Note:(1) $* * *, * * *$ indicates the significance at $1 \%, 5 \%$ and $10 \%$ level respectively;(2)11 provinces and municipality of the eastern area including Beijing, Tianjin, Hebei, Liaoning, Shanghai, Jiangsu, Zhejiang, Fujian, Shandong, Guangdong and Hainan total, 8 provinces of central areas including Shanxi, Jilin, Heilongjiang, Anhui, Jiangxi, Henan, Hubei and Hunan, 12 provinces of western region including Inner Mongolia, Guangxi, Chongqing, Sichuan, Guizhou, Yunnan,Tibet, Shaanxi, Gansu, Qinghai, Ningxia, and Xinjiang. 
Due to the estimated parameter of $\mathrm{D}(\mathrm{j}) * \ln$ finsize in $\mathrm{M}(1)$ and $M(3)$ pass the $t$ test, and the estimated parameter of $D(j)^{*}$ lnfinsize $\mathrm{E}$ in $\mathrm{M}(3)$ fails to pass $\mathrm{t}$ test, this means that financial scale in East area is conducive to manufacturing industry agglomeration, while there is No significant statistical significance on the effect of the financial scale on manufacturing industry agglomeration in the West region. Due estimated parameter of $\mathrm{D}(\mathrm{j}) *$ lnfinstru in $\mathrm{M}(4)$ is significantly negative, while the estimated parameter of $\mathrm{D}(\mathrm{j}) *$ lnfinstru in $M(5)$ and $M(6)$ fail to pass significantly t test, this indicates that the financial structure of the East region cannot adapt the agglomeration development of regional manufacturing, while we can't confirm the existence of the effects of financial structure on space agglomeration of manufacturing industry in Central and West area. Due to estimated coefficient of $D(j) *$ Infineffi in $M(7)$ is significantly negative, the estimated coefficient $D(j) * \operatorname{lnfineffi}$ of $M(8)$ is not significantly pass $t$ test, and the estimated coefficient $\mathrm{D}(\mathrm{j}) *$ Infineffi in $\mathrm{M}(9)$ is positive and significantly reject the null hypothesis, this description means that the effect of financial efficiency on manufacturing agglomeration in East area and West area are different, for the former, the lower financial efficiency is detrimental to manufacturing cluster in the East, while higher financial efficiency of the latter, a certain extent, facilitate agglomeration development of Western manufacturing industry, and the effect of financial efficiency in central on industry agglomeration can't confirm.

Further analysis of the estimated results of relevant control variables in Table 1, we found export trade, economic infrastructure, labor force, the processes of urbanization and service levels have a significant role in promoting into China's manufacturing clusters. Therefore, we can sure that, the positive role of 5-related control variables such as export trade and so on China's manufacturing industry agglomeration cannot be ignored.

\section{CONCLUSIONS}

This paper constructs the cross-provinces panel data model to analyze the effects of financial development on industrial agglomeration from the financial scale, financial structure and financial efficiency respectively. Empirical analysis shows that the effect of the financial scale, financial structure and financial efficiency on manufacturing industry agglomeration in Eastern, Central and Western region are significant differences. In which, financial scale is conducive to manufacturing agglomeration in East area, financial scale is not conducive to manufacturing agglomeration in West area, the effects of financial scale on manufacturing agglomeration is not significantly in central area. The financial structure of the East region cannot adapt the development of manufacturing agglomeration, and the effects of the financial structure of the Middle and West region on manufacturing agglomeration are not significant; the financial efficiency is not conducive to manufacturing agglomeration in the East region, the financial efficiency is conducive to manufacturing agglomeration in the West region, the effect of the financial efficiency in the Middle region on manufacturing agglomeration is not significant. In addition, we also find that the factor such as export trade, economic infrastructure, labor force, the processes of urbanization and service level and so on have experienced a significant role in the spatial agglomeration of China's manufacturing industry.

\section{ACKNOWLEDGMENT}

This article is financed by the Ministry of Education of Humanities and Social Sciences Research Youth Fund Project (No. 16YJCZH124) and the Ningbo University Research Fund Project (No. XYW15005).

\section{REFERENCES}

[1] Liu Xiuyan, Yin Xingmin \&He Xiaohai. Market potential and manufacturing space clustering: empirical study based on panel data of prefecture-level cities in China [J]. The World Economy, (1), pp.5663,2007.

[2] Han Feng \& Ke Shanzi. Spatial externalities, comparative advantages and manufacturing industrial agglomeration -an empirical analysis based on panel data of prefecture-level cities in China [J]. The Journal of Quantitative Economic and Technical Economic, (1), pp. 22-38, 2013.

[3] Wang Lide \&Fang Chuanglin. Inter-regional industrial division of labor and linkage characteristics in China [J]. Geographical Research, (8), pp. 1392-1406, 2010.

[4] Wu Sanmang\& Le Shangtong. Study on spatial distribution of manufacturing in China [J]. China's Soft Science, (6), pp.123-31, 2010.

[5] Gao Ting, Regional industrial growth: evidence from Chinese industries [J]. Regional Science and Urban Economics, 34(1), pp.101-124, 2004.

[6] Li Hanbin. The impact of FDI on China's industrial agglomeration[D]. PhD thesis of Jilin University, 2011.

[7] Lu Jiangyong \&Tao Zhigang. Determinants of industrial agglomeration in China: evidence from panel data [J]. China Economics Quarterly, (4), pp. 801-816, 2007.

[8] Bosker E., Brakman S., Garretsen H. \& Schramm M. Relaxing Hukou: increased labor mobility and China' $\mathrm{s}$ economic geography[R].SSRN Working Paper, 2010.

[9] Ma Runping. Financial development and industrial cluster: a panel data analysis based on Jiangsu province [J]. Social Sciences in Ningxia, (5), pp.38-43, 2012.

[10] Zhang Xiaodi \&Wang Yongqi. Entrepreneur and industrial agglomeration: coupling effects of the financial markets[J]. China's Industrial Economy, (5), pp.59-67, 2010.

[11] Guo B\&Duan H. International fragmentation of production, factor endowments and industrial agglomeration[J].Journal of Shanxi Finance and Economics University, (4), pp.34-43, 2011.

[12] Ran Guanghe, Wu Hao \&Shao Tengwei. Financial support for development of industrial clusters: three Western provinces (municipalities) of the empirical evidence [J]. Social Sciences in Guangdong, (3), pp.34-41, 2011. 